\title{
PESSOAL
}

\section{A Moderna Administração de Pessoal}

\author{
Benedicto Silva
}

\section{I - INTRODUÇÃo}

presente trabalho publicado no Brasil com cêrca de três anos de atraso, espelha o esfôrço feito em 1950-51 por um grupo de especialistas e estudiosos procedentes de vários países do mundo, para acrescentar algo aos princípios, métodos e práticas de administração de pessoal.

Trata-se da peça introdutória e do relatório final do Primeiro Seminário, de Administração de Pessoal realizado sob os auspícios das Nações Unidas, na cidade de Nova York, de novembro de 1950 a fevereiro de 1951. A peça introdutória, de minha autoria, constitui uma tentativa de exame panorâmico, e por isso mesmo perfunctório, dos principais aspectos e características dêsse ramo fascinante e complexo que é a moderna administração de pessoal.

O relatório que vem em seguida foi elaborado pelos componentes do Seminário. Acrescentarei, apenas para fins informativos, que o referido conclave foi planejado por mim, quando exercia as funções de assessor especial do Departamento de Assistência Técnica das Nações Unidas, em Nova York. Ao compor o discurso proferido na sessão inaugural. e que agora dou a público no Brasil, minha intenção era definir os objetivos do conclave e, ao mesmo tempo, gizar as lindes da moderna administração de pessoal.

Conforme o leitor bem informado prontamente vislumbrará o Seminário logrou passar em revista as dúvidas e focalizar as experiências de numerosos servidores públicos, alguns iniciados, outros não na teoria e prática de administração de pessoal.

Participaram do Seminário, funcionários graduados procedentes dos seguintes países: Austrália, Bélgica, Brasil, Canadá, Ceilão, China, Colômbia, Costa Rica, Dinamarca, Egito, Equador, Estados Unidos, Filipinas. Haití, Inglaterra, Israel, México, Noruega, Paquistão, Pôrto Rico e Uruguai.

A ampla distribuição geográfica dos membros do Seminário afiança, de certo modo, a universalidade de suas conclusões. As dúvidas as certezas, as indagações e os pontos de vista de todos os participantes refletem-se, com maior ou menor intensidade, nessas conclusões, tornando-as, assim mais amplas e compreensivas do que seriam. se os debatedores pertencessem a um só país ou a um número menor de países. 
O interessado encontrará, explícita e implícitamente nesse programa, alguns dos mais altos princípios e dos mais autorizados ensinamentos de administração de pessơal até agora desenvolvidos pelas práticas de vários países.

As fases em que se desdobra a administração de pessoal, desde o recrutamento até o desligamento e a inatividade, os métodos, os procedimentos suscitados pelos problemas de lotação, preparação treinamento, adaptação, disciplina, bem estar do empregado no trabalho e fora dêle, tudo isso está explícitamente indicado ou implìcitamente contido no programa elaborado pelos membros do Seminário das Nações Unidas.

Como atividade administrativa autônoma, a administração de pessoal é ainda pouco conhecida no Brasil, fora das esferas do poder público federal. Constitui, entretanto. uma das atividades institucionais mais importantes das grandes emprêsas, públicas e particulares.

E' por meio de uma boa administração de pessoal, entregue a especialistas de competência profissional ampla, atualizada e inequívoca, que as emprêsas conseguem satisfazer as três seguintes condições, sem as quais nenhum empreendimento humano pode prosperar e sobreviver: $1 .^{\mathrm{a}}$ - atrair homens e mulheres capazes e empreendedores; $2 .^{a}$ - tirar do conhecimento especializado e cepacidede de trabalho dos empregados assim atraídos os maiores rendimentos; e $3 .^{\mathrm{a}}$ - entreter as melhores relações entre supervisores e subordinados.

Em verdade, não há caminho mais seguro para robustecer e elevar os padrões de eficiência, probidade e honestidade dos serviços, sejam públicos, sejam particulares, do que a moderna administração de pessoal, que oferece solução para os complexos problemas das relações humanas no trabalho dirimindo e atenuando as conseqüências dos conflitos inevitáveis entre supervisores e subordinados, assim como entre os diferentes grupos de profissionais com antagonismos subjacentes que integram as repartições públicas, as autarquias e as grandes emprêsas privadas de nossos dias.

\section{II - PANORAMA GERAL DA ADMINISTRAÇÃO DE PESSOAL}

You as mais sinceras boas vindas aos membros dêste seminário. E' na verdade um privilégio e um prazer reunir-me a vós, para trabalharmos juntos na sede permanente das Nações Unidas. Nós, da Secretaria das Nações Unidas, esperamos que vos seja agradável e proveitosa a participação neste conclave.

Trata-se do primeiro seminário sôbre problema de administração pública patrocinado pelas Nações Unidas. Por isto aguardamos, com grande interêsse. o seu desenvolvimento e sobretudo os seus resultados finais. A permuta de experiências em tôrno desta mesa e o exame conjunto dos vossus conhecimęntos especializados de administração de pessoal dar-nos-ão preciosas indicaçõez sôbre o valor de iniciativas como esta, para os futuros programas de assistência técnica das Nações Unidas.

Incumbiram-me de falar sôbre a natureza e os objetivos dêste seminária. Limitarei minhas observações a uns poucos aspectos. 
Tratarei, em primeiro lugar, dos requisitos profissionais da administração pública de nossos dias, o que òbviamente me levará a focalizar a necessidade de estabelecer um serviço civil de carreira. Êste, por seu turno, cria automàticamente a necessidade de treinamento específico em administração pública. A focalização dêsses três tópicos justificará eu espero, a seleção de administração de pessoal como assunto do presente seminário.

\section{REQUISITOS DA MODERNA ADMINISTRAÇÃO PÚBLICA}

As múltiplas funções governamentais e os problemas que os governos enfrentam presentemente, em tôdas as partes do mundo, são de tal maneira complexos e demandam capacidade específicas e experiência profissional de calibre tão alto, que sòmente um serviço civil de competência indisputável dispõe de recursos para satisfazer às exigências da administração pública. O amador está para o desempenho das modernas funções governamentais, assim como o barbeiro está para uma operação de apendicite, isto é, tão incapaz é o barbeiro para realizar esta . quanto o amador para desempenhar aquelas.

Dizer que a maioria das funções públicas do Estado Moderno exige competência técnica de natureza especializada, é repetir um truísmo. E essa condição sòmente é satisfeita nas jurisdições administrativas em que haja uma política de pessoal positiva, deliberadamente orientada no sentido de atrair para o serviço público, e reter nêle, as maiores capacidades e os melhơres talentos existentes no respectivo agregado humano.

E' geralmente sabido que, entre as diversas condições essenciais para atrair e reter as grandes competências e os talentos verdadeiros, hoje indispensáveis ao serviço público se inclui a segurança econômica dos funcionários. A necessidade de especialização, por um lado, e o requisito da segurança econômica dos empregados, por outro, tornam imprescindível - quer isso consulte ou contrarie as nossas preferências doutrinárias - a criação de condiçốes em que o corpo de funcionários seja realmente bem selecionado e bem treinado, em base profissional e ocupacional cientificamente definida.

Meu conhecimento da administração pública de vários países que tenho visitado, anima-me a dizer. sem mêdo de errar, esta verdade, que todos reconhecem e ninguém contesta: de modo geral a maquinária governamental, inclusive nos países que se consideram desenvolvidos, não está profissionalmente equipada para desempenhar as funções especializadas - cada vez mais numerosas - e aplicar as técnicas complicadas - cada vez mais difíceis com que hoje se vê a braços o Estado.

\section{SERVIÇO PÚBLICO DE CARREIRA}

Felizmente há evidência de que a administração de pessoal em muitos países ou já foi posta em bases racionais, ou marcha para essa fase. A clássica desordem gèral e o arbítrio, que eram as características tradicionais da administração de pesšoal, estão sendo substituídos, com maior ou menor sucesso, por leis de serviço civil, regulamentos e procedimentos científicos. Ao mesmo 
tempo, os critérios desmoralizados e serôdios estão cedendo o lugar a critérios intelectuais, embora em algumas partes essa transformação se processe de modo ainda hesitante. Seja como fôr. a busca de talentos e competências para o serviço público parece universal.

Os especialistas estão de acôrdo em que o principal objetivo da moderna administração de pessoal é promover a eficácia crescente do govêrno, o que se consegue mediante: elevação da eficiência geral; custos unitários mais baixos; alto moral dos funcionários; e, por fim, melhor serviço ao público.

A adoção das técnicas e métodos da moderna administração de pessoal no serviço público requer a criação de um serviço civil e, como bem sabemos, o estabelecimento de um serviço civil pressupõe aceitação irrestrita e observância rigorosa do sistema do mérito. Sob o sistema do mérito, a admissão de candidatos ao serviço público depende invariàvelmente da verificação das respectivas habilitações. examinadas por meio de provas nitidamente definidas e bem elaboradas. Depois que o candidato ingressa no serviço pela porta do concurso digno de fé, a promoção também depende de competência específica e progressiva, inequivocamente demonstrada.

A introdução do sistema do mérito no serviço público de um país é ordinàriamente procedida ou acompanhada pela criação de um órgão central, ao qual se confiam as principais fases da administração de pessoal: o recrutamento, o treinamento, os planos de classificação e remuneração, a política de promoções, etc. O desenvolvimento adequado de um serviço civil tende a precipitar a criação de uma verdadeira carreira civil, isto é, de um serviço público de carreira.

\section{QUAIS OS CARACTERÍSTICOS DE UM SERVIÇO PÚBLICO DE CARREIRA?}

Tentando responder a essa pergunta, apresentarei a seguir uma lista dos requisitos que têm sido considerados como base de trabalho para a descrição ou definição de um moderno serviço público de carreira.

$1 .^{\circ}$ ) Todos os cargos abaixo do nível de diretor de departamento devem ser preenchidos com base no mérito e eficiência do candidato, processando-se a primeira investidura, como regra geral, através de concurso.

$\left.2 .^{\circ}\right)$ Todos os cargos deven ser meticulosamente classificados padronizando-se os vencimentos de acôrdo com os deveres e responsabilidades de cada cargo.

$3 .^{\circ}$ ) A remuneração deve ser suficiente para seduzir -os homens e mulheres mais capazes e estimulá-los a permanecer na administração.

$\left.4 .^{\circ}\right)$ O recrutamento de novos empregados deve limitar-se, tanto quanto possível, aos cargos da classe inicial de cada carreira, provendo-se os cargos mais elevados mediante promoção ou transferência.

$5^{\circ}$ ) O recrutamento deve articular-se com os vários níveis do sistema de educação pública, fixando-se limites máximos de idade para admissão a determinadas categorias de cargos e estabelecendo-se, como requisitos básicos, para ingresso no serviço, diferentes níveis de instrução geral ou liberal, ou seus equivalentes. Sòmente seria exigido treinamento técnico ou profis- 
sional, quando requerido pelo trabalho a ser executado e onde fôsse ministrado, de modo prático, pelos estabelecimentos de ensino universitários e préuniversitários.

$\left.6^{\circ}\right)$ Os concursos ou provas de habilitação devem basear-se, ampla, ainda que não exclusivamente. mas matérias ensinadas nas escolas, procurando medir de preferência a capacidade geral ou a proficiência técnica, conforme o caso, em vez do conhecimento específico do cargo a ser preenchido. Ordinàriamente, não se exigiria experiência.

$\left.7 .^{\circ}\right)$ Deve existir, em todos os ministérios ou no órgão central de pessoal, amplo programa de trein mento em serviço, destinado a preparar os novos empregados para o exercício de quaisquer funções peculiares ao serviço público ensinar os servidores, em geral, a bem desempenhar as suas atribuicões e dar-1hes oportunidade de se aperfeiçoarem, tendo em vista a promoção a cargos mais importantes.

8..$^{\circ}$ Devem-se estabe'ecer linhas definidas de promoção, a fim de assegurar, aos servidores mais capazes possibilidades razoáveis de galgarem posições de relevância. Todos os altos cargos seriam normalmente preenchidos através de promoção de elementos do próprio quadro, facilitando-se, ainda para isso as transferências de repartição para repartição e de ministério para ministério.

9. $\left.{ }^{\circ}\right)$ Essa prática poderia ser conjugada com o uso dos sistemas mais avançados de apuração do merecimento dos servidores, $\epsilon$, tanto quanto possivel, com os concursos ou provas de segunda entrância.

10. ${ }^{\circ}$ ) Articulado com o sistema de apuração do merecimento e com a antiguidade como fator de acesso haveria um sistema de melhorias periodicas de vencimentos (promoções horizontais), para recompensar a eficiência no desempenho do carro e neutralizar a desestímulo do servidor, nos casos em que, por motivos inevitáveis, a promoção demora muito ou seja improvável.

11. ${ }^{\circ}$ ) O provimento dos cargos seria em caráter efetivo ou mesmo vitalício. garantia esta cue deveria ser retirada por motivo de ineficiência ou procedimento irregular do servidor, competindo a decisão final em tais casos, a um tribunal administrativo imparcial ou organismo semelhante, para o qual caberia recurso.

12..$^{\circ}$ Deve existir um sistema de órgãos e procedimentos que assegure, efetivamente, ao servidor e seus representantes legais o direito de queixa e defesa em tôdas as disputas e conflitos resultantes da aplicação ou interpretação dos dispositivos legais e regulamentares referentes às condições de trabalho, estágio probatório, classificação de cargos, promoções e padrões de execução.

$\left.13 .^{\circ}\right)$ Deve haver um sistema liberal de seguro social, em bases atuarialmente sólidas, que abrania todos os servidores.

14. $^{\circ}$ ) O horário de trabalho, as licenças para tratamento de saúde, as férias, ' as facilidades de recreação e bem-estar assim como outras condições gerais de trabalho, seriam estabelecidas dentro de padrões elevados e liberais, de modo a constituir exemplos para as emprêsas particulares. 
A implantação e desenvolvimento adequados de um serviço público de carreira, em harmonia com os princípios gerais que acabo de esquematizar, exige a aplicação das melhores e mais recentes técnicas e métodos de administração de pessoal. As técnicas de recrutamento, por exemplo devem combinar flexibilidade com fidedignidade. A avaliação dos cargos e a administração dos vencimentos (salary administration) devem ser uniformemente extensivos a tôdas as repartições e grupos de empregados integrantes do mesmo govêrno. A participaçãa de chefes e subordinados na administração de pessoal deve ser institucionalizáda e operante. Exceto nos casos dos pequenos governos municipais, a estrutura e as funções dos órgãos de pessoal devem ser estabelecidas de acôrdo com os princípios de descentralização administrativa sob contrôle centralizado.

Acredita-se que o estabelecimento de um serviço civil de carreira, de acôrdo com êsses requisitos, constitui não sòmente o meio mais ativo de elevar o prestígio e os padrões profissionais do serviço público e manter em nível alto o moral dos servidores públicos, mas também, e acima de tudo, uma necessidade imperiosa do Estado 'Moderno. E' indiscutivel que a administra'ção pública seria a primeira beneficiária de um serviço de carreira digno dêste nome. Em primeiro lugar, a experiência mostra que o sistema do mérito atrai para o serviço público e retém nêle os candidatos mais capazes. Em segundo lugar, o sistema do mérito é a única política de pessoal que assegura e fortalece o prestígio, a integridade e a moralidade do serviço público.

\section{A NECESSIDADE DE TREINAMENTO EM REPARTIÇÃo PÚBLICA :}

Ainda não existem, na maioria dos países, escolas de administração pública. De modo geral, pode-se afirmar que os sistemas educacionais ficaram para trás, a perder de vista, em matéria de treinamento sistemático para o moderno serviço público. Há um largo fôsso entre o que o serviço público exige e o treinamento ministrado nas escolas superiores e universidades de muitos países. Em conseqüência dessa falha, o sistema do mérito não pode garantir, só por si. o recrutamento de pessoal habilitado.

Sente-se assim, cada vez mais agudamente, a necessidade de expandir e suplementar os esforços destinados a preparar homens e mulheres para o serviço público.

Conquanto o número de governos que já estabeleceram programas específicos de treinamento para os servidores públicos seja ainda muito pequeno, está claramente evidenciado, na maioria dos países, que é necessário criar e multiplicar facilidades para o treinamento especializado de candidatos ao serviço público inclusive de servidores já em exercício. A fim de preencher essa lacuna, é imprescindível que, nos governos em que a administraação de pessoal ainda esteja aquém das respectivas necessidades, sejam criados ou reorganizados órgãos de pessoal que se incumbam de desenvolver e executar, no próprio país e no estrangeiro, de modo que aproveitem a grupos numerosos de servidores públicos, programas específicos de treinamento e revisão de conhecimentos. 


\section{O PÊSO DOS VENCIMENTOS E SALÁRIOS NOS ORÇAMENTOS PÚBLICOS}

Outro fator que aumenta consideràvelmente a importância da administração de pessoal é a posição relativa dos vencimentos e salários dos servidores públicos na escala das despesas governamentais.

E' fato conhecido que os vencimentos e salários absorvem mais de $75 \%$ das despesas de custeio de alguns governos. Assim sendo é inevitável a conclusão de que quaisquer políticas, técnicas ou procedimentos, que contribuam para o aperfeiçoamento do funcionalismo em determinado país, resultam em economia considerável, deixando ao govêrno maiores recursos financeiros para aplicar nas atividades substantivas.

\section{SEMINÁRIO SÔBRE ADMINISTRAÇÃO DE PESSOAL}

As observações feitas mostram algumas das razões que nos levaram a considerar desejável fôsse a administração de pessoal o assunto do primeiro seminário da série que as Nações Unidas pretendem realizar sôbre problemas de administração pública.

Todos sabemos, entretanto, que a administração de pessoal ainda não é um campo profissionalizado. Em alguns países, nem mesmo chega a ser uma atividade institucionalizada. Ainda assim, a messe de conhecimentos sôbre o assunto já é tão grande, que permite discussão e permuta de idéias e pontos de vista por parte de pessoas do calibre das que se encontram em tôrno desta mesa.

Cơmo fôstes selecionados dentre funcionários públicos engajados em administração de pessoal, tudo leva a crer que tenhais problemas e interêsses em comum e muito que aprender uns com os outros. Uma vez que o seminário foi planejado para abranger os assuntos principais de um programa de administração de pessoal, as discussões e leituras absorverão grande parte de vosso tempo.

Não será utilizado aqui nenhum material com o fim de recomendar princípios, processos ou práticas identificados com qualquer país ou grupo de países. Todo o material que temos à vossa disposição será usado exclusivamente para ilustrar os tópicos focalizados, ou para dar vivacidade e conteúdo real às discussões. O propósito essencial das discussões é apontar e examinar. compreender e avaliar, no tocante a cada problema de administração de pessoal que aqui focalizarmos, um certo número de soluções (tanto as aceitáveis como as inaceitáveis), desenvolvidas por técnicos e por órgãos de pessoal em diversos países e em organizações internacionais.

Alguns especialistas de incontestável saber no assunto foram convocados para realizar palestras sôbre os tópicos mais importantes do seminário. Êsses especialistas limitar-se-ão a versar os princípios aplicáveis e os problemas relacionádos com o assunto particular que fôr distribuído a cada um.

As várias aplicações práticas dơs princípios expostos nas conferências serão convertidas em assuntos para as discussões subseqüentes, nas quais espe- 
ramos que todos os membros do seminário participem efetivamente, suscitando problemas e apresentando sugestões.

Depois que concluirmos os trabalhos do seminário, uma análise das discussões será levada a efeitơ pelo Secretariado das Nações Unidas para o fim de expandir os recursos informativos que possam ser utilizados em futurcs seminários sôbre a administração de pessoal igualmente organizados sob cs auspícios das Nações Unidas.

Um relatório minucioso dos trabalhos do seminário será também elaborado pelo Secretariado para servir como material informativo adicional, capaz de enriquecer o fundo internacional de conhecimentos sôbre problemas e princípios de administração de pessoal.

O presente seminário será conduzido em harmonia com o princípio diretor de que o estabelecimento, reorganização ou modernização do serviço civil constitui uma necessidade urgente de muitos países. Cumpre resolvê-la para que os servidores públicos desempenhem com eficiência as crescentes funções que em nossos dias recaem sôbre os ombros do govêrno.

\section{A OPORTUNIDADE DE DEBATER SÔBRE ADMINISTRAÇÃO PÚBLICA}

E' óbvio que um seminário isolado sôbre administração de pessoal ou sôbre qualquer outro problema administrativo teria escassa repercussão. Uma iniciativa como esta sòmente pagará dividendos satisfatórios, se funcionar como foco de germinação, abrindo caminho para outros seminários, a serem realizados durante certo número de anos, em várias partes do mundo.

Fazemos bons augúrios para que essa série compreenda outros seminários sôbre administração de pessoal, organizados em base regional, assim como seminários sôbre outros problemas administrativos, por exemplo: orçamento público, administração de material, administração financeira, organização e métodos, govêrno municipal, etc. E' desejável que um plano similar de seminário sôbre os aspectos administrativos das atividades funcionais do govêrno seja igualmente estabelecido como parte do programa de assistência técnica das Nações Unidas. Os seminários sôbre atividades funcionais do govêrno poderão ocupar-se de matérias como a organização e $\alpha$ funcionamento dos departamentos de saúde pública ministérios de obras públicas, comunicações, serviços de polícia, educação, utilidades públicas, instituições de bem-estar social, etc.

Além dêsses, outros seminários regionais sôbre problemas de administraçăo diretamente ligados aos projetos de assistência técnica das Nações Unidas deveriam ser organizados em benefício de grupos de especialistas, procedentes dos diferentes países aos quais seja prestada assistência.

As matérias preparadas para um seminário deverão ser constantemente revistas e melhoradas à luz dos resultados obtidos nas discussões havidas para utilização, outras vêzes, nos futuros seminários sôbre o mesmo assunto.

Seguindo tal curso de ação, com a vossa ajuda e a ajuda de outros grupos semelhantes, em poucos anos as Nações Unidas terão acumulado um fundo valiosíssimo de conhecimentos e de material de ensino sôbre os vários campos 
da administração pública. Êsse material, experimentado uma e mais vêzes, corrigido e revisto à luz de sua eficácia poderá ser traduzido para vários idiomas e pôsto à disposição de todos os países, para ser adaptado e utilizado em seminários nacionais e quiça em benefício de servidores públicos de distintas jurisdições, como estados, províncias, comunas e municípios. E' razoável esperar destas atividades, assim organizadas, o advento de uma série de seminários de alta classe sôbre administração pública, realizados sob os auspícios das Nações Unidas.

Desejamos ardentemente que o impacto dêste programa na administração pública repercuta em todos os níveis de govêrno através do mundo e constitua outra grande contribuição das Nações Unidas para a compreensão e a cooperação internacionais.

\section{RELATÓRIO DO PRIMEIRO SEMINÁRIO DAS NAÇÕES UNIDAS SOOBRE ADMINISTRAÇÃO DE PESSOAL}

\section{INTRODUÇÃO}

Este relatório contém as conclusões a respeito dos vários aspectos da administração pública de pessoal que foram consideradas pelo seminário durante a sua reunião em janeiro de 1951.

Trata-se de um documento meramente orientador e algumas de suas conclusões não foram aprovadas por unanimidade. Muitas delas não são mais do que a opinião pessoal da maioria dos membros do seminário e não podem, portanto, ter como responsável uma qualquer administração ou indivíduo em particular.

A leitura dêste relatório deveria ser feita em conjunto com a das atas das reuniões que incluem informações detalhadas sôbre muitos dos tópicos e os pontos acêrca dos quais houve divergência de opinião.

\section{ORGANIZAÇÃO E FUNÇÕES DOS SERVIÇOS DE PESSOAL}

1. A eficiência e a integridade do serviço público são essenciais a um bom govêrno e exigem sistemas de pessoal eficientes que assegurem a existência de padrões elevados. Os principais objetivos de tais sistemas de pessoal devem ser: recrutar e conservar funcionários da mais alta competência c integridade e conseguir do pessoal eficiência, cada vez maior, proporcionando, conseqüentemente, melhores serviços ao público com menores gastos.

2. Deve haver, preferivelmente, um órgão central de pessoal que dirija um programa organizado e equitativo de administração de pessoal para empregados do govêrno. A execução da administração, contudo, pode ser centralizada ou descentralizada. O grau de centralização ou descentralização poderá variar de acôrdo com as circunstâncias locais e, possivelmente, com os tipos de funç̧ão.

(1) O têrmo "serviço" é usado em sentido genêrico, não correspondendo necessàriamente à nomenclatura usada na administração pública brasileira. 
3. Os serviços de pessoal devem ser despidos de todo preconceito e investidos de autoridade adequada; devem possuir um corpo de funcionários đe categoria e a necessária verba que lhes permita realizar sua missão. $O$ órgão central de pessoal deve ser independente tanto quanto possível e isento de influências políticas ou quaisquer outras influências prejudiciais, embora deva obedecer ao contrôle geral do govêrno na formulação das políticas a seguir.

4. O órgão central de pessoal deve ser responsável pela preparação de estatutos, regulamentos e instruções aplicáveis ao funcionalismo público em geral. Aos funcionários deverá ser dada a oportunidade de colaborar no preparo de leis referentes à administração de pessoal e de comentá-las. Mas, especificamente, o órgão central de pessoal de um govêrno deve ser responsável pelo funcionamento eficiente da administração de pessoal baseada no princípio do mérito e nas práticas modernas aplicáveis ao recrutamento, seleção, promoção, exoneração, classificação de cargos, planos de vencimentos, treinamento, disciplina, aposentadoria, horários de trabalho, licenças, e outros tópicos referentes ao serviço público. Tôdas estas atividades podem ser adequadamente realizadas mediante sistemas centralizados ou descentralizados.

5. Para garantir a independência do órgão central de pessoal, com relação a influências perniciosaș:

a) o chefe ou diretor do órgão central de pessoal não deve estar sujeito a remoções motivadas por mudanças políticas no govêrno;

b) o período para o qual é nomeado o diretor do órgão central de pessoal, ou a junta diretora dêsse órgão, deve ser prefixado (poderá abranger um determinado número de anos ou ir até a idade de aposentadoria compulsória). Este cargo poderá também ser de carreira com a estabilidade habitual;

c) o chefe ou diretor do órgão central de pessoal, assim como os membros da junta diretora não devem ter outros cargos ou funções remuneradas na administração pública.

6. O órgão central de pessoal deve estar situado dentro da estrutura governamental em posição tal que lhe confira máxima autoridade e independência.

\section{CLASSIFICAÇÃo DE CARGOS, SALÁRIOS E VENCIMENTOS}

7. Para que os servidores públicos de qualquer jurisdição recebam tratamento idêntico e justo, é necessário haver um sistema cuidadosamente elaborado de classificação de cargos e atribuições de salários e vencimentos adequados aos respectivos cargos ou funções.

8. Nos últimos anos, muitos foram os que se dedicaram aos problemas de classificação de cargos e de planos de remuneração, abordando êstes assuntos de diferentes ângulos e usando diferentes métodos. $O$ material assim acumulado é de grande utilidade para todos os administradores que se interessam por aquêles problemas. Os diversos métodos seguidos, contudo, convergem para o mesmo ponto: determinam as atribuições e deveres de cada 
cargo ou função, nos diferentes níveis de classificação. Os diversos tipos de trabalhos ou atribuições podem ser administrados diretamente por um órgão central de pessoal, que determina a classificação de todos os cargos, ou divulgados pelo mesmo órgão para uso e orientação dos órgãos seccionais de pessoal, aos quais caberá então a missão de classificar os cargos.

9. A primeira coisa a considerar ao estabelecer-se um plano de classificação de cargos é a natureza dos deveres e responsabilidades de cada cargo, sem levar em conta a pessoa que poderá vir a ocupá-lo.

10. Eis os pontos essenciais de um plano de classificação: cargo;

a) análise objetiva e avaliação dos deveres e responsabilidades de cada

b) os cargos devem ser agrupados em classes, tendo por base, a igualdade de deveres e responsabilidades. As classes devem ser estanque, isto é, uma não deverá interferir nas atribuições de outra; classe;

c) definir, em têrmos gerais, os principais característicos de cada

d) prever uma correlação adequada entre as classes de cargos, a fim de permitir o estabelecimento de níveis de supervisão apropriados e possibilitar a promoção dos servidores;

e) flexibilidade do plano, tendo em vista permitir revisões na classificação, a fim de adaptá-la a novas situações.

11. A natureza das obrigações ou atribuições do funcionário é que determinará o nível de seus vencimentos. Quanto mais difícil e de maior responsabilidade fôr determinado trabalho, tanto mais bem pago deverá ser seu executante. Dentro de uma mesma jurisdição, todos aquêles que executarem trabalhos semelhantes deverão receber salários ou vencimentos eqüivalentes.

12. Grupos ou classes de remuneração, dentro dos quais haja um escalonamento - isto é, recebimento, por parte do funcionário, de maior quantia, sem sair da própria classe, ou seja, sem promoção, - devem substituir os padrões ou referências fixos. Apenas nos casos das classes mais elevadas, haverá situações em que será preferível optar por vencimentos fixos.

13. Deve-se prever a possibilidade de revisões dos escalonamentos de vencimentos, para fazer face a mudanças na situação econômica.

14. Gratificações devem ser pagas sòmente quando o trabalho realizado fôr de natureza perigosa para a saúde ou integridade física do servidor. Estas gratificações serão consideradas à parte das remunerações básicas previstas no plano.

15, O govêrno deve procurar pagar ordenados que atraiam novos servidores e tenham poder de manter no serviço público o pessoal habilitado, permitindo-lhe um padrão de vida razoável. Para tal fim, levará principalmente em conta os salários pagos nas emprêsas privadas. 


\section{RECRUTAMENTO E SELEÇÃo}

16. O govêrno deve esforçar-se por atrair, recrutar e selecionar para as atividades de carreira as pessoas mais aptas para o desempenho dos serviços públicos, encorajando-as a fazer carreira nessas atividades. Isto porque o sucesso e a eficiência da administração dependem, em grau apreciável, da capacidade e da integridade dos servidores públicos, que são os executores dos programas.

17. A seleção deve obedécer exclusivamente ao princípio do mérito. O aproveitamento de pessoas no serviço público por mera conveniência política ou por favoritismo é a antítese do sistema do mérito.

18. E de extrema importância estabelecer uma distinção nítida entre os cargos políticos e os cargos do serviço civil. A nomeação de pessoas para cargos de carreira deve basear-se, em todos os casos, no sistema do mérito, excetuados os cargos de alto nível, como, por exemplo, as pastas ministeriais.

19. A seleção de funcionários para os cargos de carreira deve observar a prática de concursos abertos a todos. Os serviços de pessoal devem divulgar com clareza e antecedência todos os dados referentes aos concursos: data, lugar, requisitos e outras informações de importância capital.

20. Antes de qualquer processo de seleção é necessário empreender um programa bem planejado de recrutamento, cuja finalidade será atrair para o serviço público as pessoas que reunam as mais altas habilitações. Para meIhores resultados, as secções competentes devem estabelecer relações com as universidades, colégios, associações profissionais e o público em geral.

21. Os serviços de pessoal devem manter, em seu corpo de funcionários, técnicos especializados na preparação e correção das provas a que serão submetidos os candidatos, assegurando desta forma a validade dos concursos. Além destas atribuições, os ditos técnicos, devem ficar incumbidos de realizar pesquisas que conduzam não só ao aperfeiçoamento das técnicas existentes como também à elaboração de novas técnicas.

22. As secções éncarregadas do recrutamento devem adotar os métodos que julgarem mais convenientes para aplicação do sistema de mérito na seleção de candidatos. De acôrdo com as circunstâncias, optarão entre os exames escritos, exames orais, testes de execução e entrevistas para verificar a experiência e o nível de instrução dos candidatos. Além disto, também é aconseIhável realizar: aptos;

a) exames médicos, para assegurar a seleção de candidatos fìsicamente

b) inquéritos ou investigações objetivas e fidedignas sôbre o caráter, integridade e reputação dos candidatos antes de serem definitivamente admitidos ao serviço público.

23. Cargos de natureza permanente, podem ser providos temporàriamente sem concurso, mas só em circunstâncias especiais, como seja, em caso 
de urgência, e sob severo contrôle, de modo a salvaguardar intato o sistema de mérito.

24. Os funcionários interinos (temporários) devem adquirir efetividade depois que provarem suas habilitações em concursos.

25. O lugar de nascimento ou moradia do candidato não deve ser levado em consideração quando se tratar de funções da alçada federal. Contudo, em se tratando de serviço regional ou municipal, é preferível ater-se aos residentes no local ou aos naturais do lugar ou região. A extensão da área geográfica de recrutamento depende do número de candidatos qualificados na região ou cidade.

26. O serviço de recrutamento deve conjugar-se com o serviço de classificação para estabelecer os vários requesitos para os diversos cargos, de acôrdo com o plano geral de classificação. Os requisitos devem possuir flexibilidade e fazerem-se acompanhar de modificações no plano de classificação.

27. O estágio probatório é um dos aspectos mais recomendáveis do processo de seleção.

28. Quando os cargos puderem ser preenchidos indiferentemente por candidatos de ambos os sexos, deve ser-lhes dada oportunidade de competir em igualdade de condições.

\section{AVALIAÇÃO DA EFICIÊNCIA DO SERVIDOR}

29. Para servir aos próprios interêsses da administração e dos funcionários, deve-se proceder a um sistema analítico de avaliação da eficiência dêstes últimos. Tal processo ficará a cargo dos funcionários mais graduados, que apurarão fatos referentes à capacidade, progresso, desempenho, e potencialidade do corpo de funcionários. Estas informações serão de grande valia para fundamentar as promoções, as transferências, o treinamento, a exoneração ou outros procedimentos administrativos. Quando utilizadas convenientemente, as informações obtidas contribuem amplamente para a eficiência dos funcionários e para a melhoria geral dos serviços.

30. Quando as avaliações são realizadas mediante atribuição de pontos (notas), podemos denominá-las "boletins de merecimento", "graus de aproveitamento", "graus de eficiência", etc. As diversas formas de relacionar os graus de merecimento, ora em uso, podem ser melhoradas. Muitas seções fazem seus relatórios utilizando um boletim comum a todos os funcionários, quaisquer que sejam seus níveis ou classes. Sugerimos, porém, que:

a) os boletins não sejam utilizados em casos de funcionários de nível elevado;

b) se ressaltem os diferentes fatôres para os diferentes cargos e classes, já que os requisitos diferem de um para outro, como, por exemplo, nos casos de escriturários e dactilógrafos.

31. O sistema de avaliação tem sua eficiência condicionada pela capacidade e pela objetividade do encarregado dêste processo. $\mathbf{E}$ de suma impor- 
tância, por isso, que seja êle submetido a um treinamento adequado. Entre os: deveres do avaliador encontram-se:

a) o de informar aos funcionários acêrca de seus deveres e dos requisitos de seu cargo;

b) o de conferenciar, sempre que necessário, com os servidores, pondoos a par da medida em que têm demonstrado aproveitamento compativel com os requisitos de suas funções;

c) o de demonstrar a necessidade de trabalhar com eficiência e, especialmente, indicar-lhes suas deficiências e o meio de superá-las atraás de treinamento apropriado.

32. Existindo sistemas de avaliação, os funcionários devem ser postos: a par dos pontos (graus) obtidos, possibilitando-se-lhes, mediante providências adequadas, pedir reconsideração de um julgamento desfavorável.

33. Outro tipo importante de avaliação de eficiência é o relatório preparado no fim do período probatório. Alguns países utilizam formulários padronizados. Todavia, os princípios fundamentais de avaliação são os mesmos, e cremos ser mais importante ainda, para benefício de todos os serviços em conjunto, preparar relatórios objetivos e detalhados, logo após o estágio probatório.

\section{PROMOÇÃo}

34. Os sistemas ou regulamentos de promoção adotados por uma repartição são de máxima importância na administração de pessoal, pois na promoção reside um dos estímulos mais tonificantes do moral do pessoal. 0 recrutamento é também favorecido quando existem boas perspectivas de promoção.

35. O sistema de promoção deve ser bem organizado, justo, e deve satisfazer à maioria dos funcionários, especialmente no que se refere à imparcialidade na seleção dos que vão ser promovidos.

36. O fundamento mais sólido do sistema de promoção é o princípio do mérito. No caso de igualdade de competência e capacidade de trabalho, promovam-se de preferência os funcionários mais antigos. Algumas repartições preferem a promoção por antiguidade. Havendo um número limitado de cargos, especialmente os situados nos níveis inferiores, é possível optar pela promoção do funcionário eficiente mais antigo, em benefício do moral dos funcionários e sem prejudicar a eficiência do serviço.

37. Tomando-se o mérito por base, a seleção do melhor candidato à promoção poderá ser realizada mediante os boletins de merecimento, provas de promoção, entrevistas feitas por uma junta ou qualquer outro método de seleção. Para os funcionários que se julgarem prejudicados, deve haver um sistema ou dispositivo que os habilitem a pedir reconsideração de seus casos, exceto quando as promoções forem baseadas em processos por si próprios passíveis de revisão, como é o caso das provas e das avaliações de eficiência. 
38. Um plano geral de promoções deve prever o recrutamento de novos funcionários para preenchimento de vagas no início da carreira. Os candidatos aprovados devem ser então treinados para desempenhar funções mais graduadas, assegurando-se-lhes oportunidades de promoção. As vagas existentes nas classes superiores devem ser providas por funcionários da própria repartição.

39. Em algumas jurisdições, o órgão central do pessoal é incumbido de proceder à revisão das promoções, para que não haja dúvidas quanto à equanimidade e à justiça das promoções efetuadas. Recomenda-se êste método para aquelas jurisdições em que as práticas modernas de administração de pessoal ainda estão pouco desenvolvidas ou arraigadas, o que torna injustificável delegar a seções ou repartições locais a autoridade de promover funcionários.

\section{LOTAÇÃO}

40. A lotação correta do funcionário é fundamental na administração de pessoal, devendo ser observada desde a primeira designação, nas transferências, promoções e rebaixamentos. As seções de pessoal devem lotar os funcionários nos postos em que poderão ser mais eficientes, ficarão perfeitamente ajustados e poderão ter possibilidades de promoção. Quando a lotação é bem feita, o funcionário terá seu moral e sua eficiência beneficiados.

41. Aconselha-se a movimentação horizontal dos funcionários, isto é, as remoçõ̀es, a fim de lhes proporcionar experiências em diversos setores, possibilitando, desta forma, flexibilidade e maior interçambio dentro do serviço.

\section{TREINAMENTO DE SERVIDORES PÚBLICOS}

42. O treinamento dos funcionários é uma importante atribuição dos serviços de pessoal, pois proporciona à direção um meio de ensinar aos funcionários o modo de se desincumbirem de suas tarefas com maior eficiência. Permite, ainda, que os funcionários mantenham e desenvolvam sua capacidade e eficiência, e habilita-os a desenvolverem as respectivas aptidões para aplicá-las em atividades mais complexas e de nível mais eleavdo. Os métodos de organização do treinamento diferem de país em país, de acôrdo com as condições locais. De modo geral, porém, o órgão central de pessoal é o que está mais habilitado a coordenar, orientar e suprir de recursos técnicos os órgãos departamentais de pessoal neste aspecto da administração.

43. Os programas de treinamento do pesosal são especialmente necessários naqueles países em que o sistema educacional não esteja bem aparelhado. Em muitos países, êsses programas revelam-se extremamente úteis, por sanarem as lacunas no treinamento e na experiência anteriores dos funcionários.

44. O treinamento deve ser planejado de forma eficiente e sistemática e, na maioria dos casos, convém ser executado pelos órgãos seccionais de pessoal. Alguns cursos, porém, (por exemplo: cursos para pequenos grupos de 
alunos, pertencentes a diversos departamentos) devem ficar sob a direção do órgão central do pessoal.

45. Cursos formais de treinamento devem ser dados somente quando houver uma necessidade clara do serviço, quer por parte dos órgãos executores, quer pelos órgãos diretores. Os diretores e os supervisores devem procurar sempre verificar as necessidades de treinamento de seus funcionários.

46. Os cursos de treinamento dos departamentos devem ser dirigidos pelos órgãos de linha, aconselhando-se, porém, a designação de um especialista para planejar e organizar tais cursos.

47. O treinamento pode abranger cursos prévios, treinamento em serviço, cursos especiais, cursos de correspondência, cursos de aperfeiçoamento, cursos de universidades ou outras instituições fora do serviço público, e ainda outros tipos apropriados. Todos êstes tipos se distribuem por três setores principai:

a) Treinamento prévio - Para benefício do público, o govêrno deve incentivar as instituições educacionais a oferecerem a instrução necessária a futuros candidatos ao serviço público, para que os mesmos obtenham formação e experiência adequadas;

b) Treinamento de iniciação no serviço (induction training) - $O$ treinamento adequado dos novos funcionários é de importância capital. De modo geral, o treinamento de iniciação terá por objetivo dar-lhes uma idéia geral da organização de sua repartição e do govêrno, assim como do enquadramento de seus postos na organização. Os novos funcionários deverão, também, ser treinados amplamente nos trabalhos que irão realizar e receber detalhadas informações sôbre os direitos e privilégios do funcionário público.

c) Treinamento em serviço - A natureza dos cursos depende do tipo de atividade da repartição, mas devem êles integrar-se num plano geral cujo obejtivo seja o de desenvolver os conhecimentos e o interêsse dos funcionários, no que toca à função de cada qual e às funções dos colegas. Nesta fase, deve-se dedicar especial atenção à administração pública em seu mais ampln sentido. Do programa constarão visitas a instituições e organizações integrantes do departamento a que pertençam os funcionários. Este método desperta grande interêsse entre êles. Recomenda-se a utilização intensiva de filmes, bibliotecas e outras técnicas.

48. Visto que o supervisor depende muito do pessoal sob sua jurisdição, torna-se parte importante de seu trabalho conseguir que os funcionários desempenhem o melhor possível as suas funções. Esta habilidade de orientar com êxito é um dos requisitos do cargo de supervisor, pelo que deve merecer especial atenção quando da seleção e treinamento de supervisores.

49. Sempre que possível, o treinamento de iniciação e o treinamento em serviço devem realizar-se durante os horários regulares de trabalho.

50. Muitos países adotam a prática de conceder licenças de estudo, sem perda de vencimentos, em alguns casos, para que funcionários selecionados possam seguir cursos de especialização no próprio país ou no estrangeiro. Eis uma prática elogiável e muito recomendada. 


\section{RELAÇÕES COM OS FUNCIONÁRIOS}

51. O elemento mais importante de qualquer organização, pública out particular, é o elemento humano que a compõe. A eficiência com que trabalham em conjunto, o modo como são dirigidos os funcionários e a habilidade de cada um na realização de seus trabalhos são fatôres que influem grandemente na eficiência e produtividade. Conseqüentemente, as seções que lidam com o pessoal devem dedicar especial atenção ao desenvolvimento das qualidades de chefia e ao moral dos funcionários. Convém lembrar, especialmente, que as relações diárias entre funcionários e supervisores se devem basear no fato de que todos êles são humanos e merecem um, tratamento respeitoso e justo.

52. Tôdas as repartições públicas devem manter relações adequadas: entre os dirigentes e os subordinados, em benefício da administração e dos funcionários. Cumpre, porém, que tais considerações não sejam levadas ao exagêro, isto é, que só importem os desejos e o confôrto do funcionário, em detrimento dos direitos do público.

53. Uma das importantes responsabilidades dos serviços de pessoal deve ser a de entrevistas com os funcionários para discussão de seus problemas pessoais e das dificuldades oriundas de seus trabalhos.

54. O moral do funcionalismo não depende exclusivamente de considerações de ordem econômica, embora estas sejam de extrema importância. E necessário que os funcionários trabalhem em ambientes adequados, que tenham uma sensação de segurança e de participação efetiva como membros. de uma organização útil e eficiente. Tudo isto contribui para que o funcionário se sinta satisfeito em seu emprêgo. Outras condições importantes: o horário razoável, férias e licenças para tratamento de saúde, segurança contra acidentes e indenizações por acidentes no trabalho.

55. Os servidores públicos devem ter a liberdade de se filiarem ou não a qualquer associação profissional de sua classe, contanto que seja legal.

56. Em alguns países existe um sistema apropriado de negociações e consultas entre a administração e as associações profissionais de servidores. públicos. A existência de tal sistema é desejável em países onde existam, ou possam ser criados, tais organismos profissionais. São de grande valia os tribunais de arbitramento, cuja finalidade é resolver disputas entre as associações de funcionários e a administração.

57. O direito de greve é incompativel com os deveres fundamentais do servidor público.

58. A direção deve incentivar as atividades recreativas, sociais e de assistência e as organizações de funcionários.

59. Ùltimamente vem-se recorrendo, em alguns países, a sistemas de prêmios aqs funcionários eficientes e à aceitação de sugestões por parte dos funcionários. Recomenda-se tal prática como meio de participação mais intensa dos funcionários nos negócios públicos e de criar interêsse maior na eficiência e no rendimento de seus serviços 


\section{DISCIPLINA}

60. Os servidores públicos devem ser considerados, em primeiro lugar, como cidadãos do Estado, com os mesmos direitos e deveres dos outros cidadãos. Devem obediência à lei do país se como tal, estão sujeitos às mesmas sanções penais e civís a que se submetem seus concidadãos.

61. Uma honesta disciplina é fundamental à manutenção de um alto padrão moral. O servidor público deve ser disciplinado dentro da repartição e fora dela. Sua reputação pessoal deve estar acima de qualquer crítica. A ação disciplinar, contudo, só deverá aplicar-se nos casos de atos ou formas de comportamento que se reflitam diretamente na vida pública do servidor, comprometendo sua condição de funcionário do govêrno.

62. O público será melhor servido se os funcionários receberem tratamento justo e equânime. Por outro lado, espera-se que o funcionário respeite escrupulosamente as normas estabelecidas, retribuindo as atenções que the săo dispensadas mediante um serviço altamente eficiente.

63. Os supervisores, sem distinção de nível, devem ser os primeiros a dar o exemplo de exato cumprimento das instruções, regulamentos e normas de conduta pessoal, para que os funcionários também assim procedam. Cumpre adotar medidas disciplinares quando verificadas a falta de cumprimento dos deveres por parte dos funcionários, seja por negligência, incapacidade ou má vontade.

64. Quando fôr necessário recorrer a medidas disciplinares, sòmente o caso em si deve importar. Cumpre pôr de lado os fatôres tais como: raça, posição social, credos políticos ou religiosos ou qualquer outra circunstância que não esteja relacionada com o mérito do caso. As quebras de disciplina, quando equivalentes, devem ser punidas com igual rigor.

65. Os funcionários devem ser informados de antemão sôbre as medidas disciplinares a serem tomadas contra êles, dando-se-lhes oportunidade de se defenderem. Quando não se tratar de ligeiros casos de indisciplina, o funchonário deverá ter o direito de apelar contra a decisão tomada .

\section{APOSENTADORIA}

66. No interêsse da administração e dos funcionários, deve haver uma idade para aposentadoria compulsória, qualquer que seja a repartição em que estiverem lotados os funcionários.

67. As instituições de administração pública devem estabelecer planos de aposentadoria e pensões dos servidores do Estado, quer êstes contribuam oiı não para êste fim. Tais planos devem aplicar-se exclusivamente ao funcionalismo público, mas podem fazer parte de um programa nacional de assistência.

68. Quando os funcionários são compelidos a contribuir para as caixas de pensñes e aposentadoria, devem estar representados nas Juntas ou Institutos que regulam as pensões, se tais Juntas ou Institutos existirem. 
69. Os regulamentos e os fundos das caixas de pensões devem ser administrados por um órgão central em cada jurisdição. A administração ficará responsável pelos deficits encontrados nos fundos para pensões.

70. Quer os funcionários contribuam ou não para as caixas de pensões, os regulamentos devem prever o direito dos mesmos às pensões, se forem aposentados por motivos de saúde.

71. Os planos de pensões devem prever o pagamento de pensóes às espôsas e aos dependentes mais próximos, em caso de morte do servidor, observadas as exigências de habilitação.

72. As pensões devem ser revistas e ajustadas sempre que se tornar necessário, tendo em vista modificações nas condições econômicas.

73. Quando fôr adotado o sistema de contribuição compulsória para os fundos de aposentadoria, dando-se o caso de exonerar-se o funcionário antes da idade compulsória, terá êle direito à restituição de suas contribuições.

74. Em benefício do serviço, deve-se prever a aposentadoria de um funcionário que conte muitos anos no serviço público, (mas que não tenha atingido a idade compulsória) cuja eficiência esteja sensivelmente diminuída, mas não ao ponto de justificar sua demissão.

\section{ESTABILIDADE}

75. Os funcionários públicos devem ser protegidos contra demissões ou exonerações arbitrárias, como é o caso de dispensa por motivos políticos: Por outro lado, o sistema de proteção dos direitos do funcionário não deve ser rígido ao ponto de impossibilitar a dispensa imediata de funcionários incompetentes.

76. Dando-se o caso de redução no número de funcionários de uma repartição permanente, ou extinção de cargos ou repartições, ou funcionários excedentes, de reconhecida capacidade, deverão ser removidos para outras repartições sem promoção ou rebaixamento. Não sendo isso possível, tais funcionários serão considerados em disponibilidade por extinção de cargo. Caso não esteja prevista essa modalidade, tudo deve ser feito para lotá-los em quaisquer outras repartições públicas.

\section{SAÚdE E SEguRANÇA}

77. A experiência demonstra que a eficiência e o rendimento dos serviços públicos são beneficiados pela redução de acidentes e de faltas por motivo de doença. Por esta razão, devem ser estabelecidos planos sistemáticos de assistência e previdência que protejam o funcionário público.

78. Funcionários que se tornem incapacitados para o trabalho no exercício de sua função devem receber tôda a assistência e proteção durante o período de incapacidade. 


\section{HORÁRIO DE TRABALHO}

79. O horário de trabalho do funcionalismo público não deve ser mais extenso nem sensivelmente menor do que os horários da indústria e do comércio.

80. O expediente poderá ser prorrogado e, quando o fôr, os funcionários deverão receber as horas extraordinárias.

\section{LICENÇAS}

81. Os funcionários públicos devem ter direito a licença sem perda de vencimentos. Neste capítulo incluem-se as férias e a licença para tratamento de saúde. Os funcionários devem ser instados a gozar as férias a que tiverem direito.

\section{SUMMARY}

1. The above writing comprises (1) a Report of the First Seminar on Personnel administration held in New York (november 1950-february 1951) under the auspices of the United Nations; (2) an Introductory Address delivered by Mr. Benedicto Silva, Special Assessor to the Department of Technical Assistance of the United Nations.

2. The Introduction stresses the following points: (1) The complexity of the government functions and problems requires a civil service of recognized competence, there being in it no place for the amatcur; (2) The recruiting of a variety of specialized people, possessed of specific technical competence should be made through a positive personnel policy capable of attracting the best talents as well as of providing conditions of a good selection and sound training of candidates; (3) The absence of organization and the prevalence of discretion and nepotism are traditional characteristics of personnel administration procedures; (4) The purpose of administration is greater government efficiency through (a) improved general efficiency, (b) lower unit costs of operation, (c) higher employee methods of modern personnel administration requires the establishment of a civil service based on the unrestricted acceptance and rigid observance of the merit system; (6) The adoption and development of the career system, involving the best and more recent techniques and methods of personnel administration, is not only the more effective means of increasing the prestige and the professional standards of the civil service and of maintaining a high level of morale among the employees; it is also an imperative of the modern State; (7) Characteristics of the career system minutely analized; (8) The educational systems lag, on the whole, far behind the necessity of systematic training for the modern civil service; a small number of governments offer special training programmes for civil servants, but facilities both for preservice and in-service training should be created and multiplied; (9) Salaries and wages account for more than $75 \%$ of the expenditures of the civil service will obviously result in considerable economy; (10) Personnel administration is not a professionalized field as yet; in some countries it is not even an institutionalized activity; (11) The seminar has been planned to cover the main aspects of a programme of personnel administration; no material is to be used with the purpose of recommenting principles, procedures or practices but rather as illustrations to topics for discussion; well-known specialists have been invited to address the members of the Seminar and upon conclusion of the same, and analysis of the discussions is to be made by the Secretariat (12) The Seminar is the atarting point for discussion and thinking in order to pave the way to future seminars; other desirable seminars on personnel administration should be organized on regional bases, as well as seminars on other administrative problems, such as public budgeting, materiel administration, finance administration, organization and methods, municipal government, etc.; (13) The desirability of a similar plan of seminars on the administrative aspects of the functional activities of the government, viz., public health, public works, communication, police services, education, public utilities, social welfare, etc.; regional seminars on administrative problems directly related to the projects of technical 
assistance of the United Nations should also be held; (14) The cumulative knowledge and the teaching materials on the various fields of public administration to be obtained by the United Nations through the seminars; experimentation and revision are to be planned aiming at the publication of translations of reports and recommendations to be adapted and utilized in national or even local seminars.

3. The Report embodies the eighty-one conclusions on several aspects of public personnel administration reached at by the Seminar, as follows:

\section{ORGANIZATION AND FUNCTIONS OF PERSONNEL SERVICES}

(1) Conditions of efficiency and integrity of the civil service.

(2) Necessity of a central public personnel agency.

(3) Personnel agencies should be free from prejudices and from political or any other harmful influences; their authority, staffing and financial bases.

(4) Responsibilities of central personnel agencies defined.

(5) Conditions of appointment and tenure of personnel officers.

(6) Placement of central personnel agencies within the government structure.

\section{POSITION CLASSIFICATION, WAGE AND SALARY ADMINISTRATION}

(7) Necessity of a system of position classification and pay plans.

8) Different methods of approach to the problem of determining the duties of every position in the classification plan.

(9) The duties and responsibilities of each position objectively considered.

(10) The five essential aspects of a classification plan.

(11) Salarias to be fixed according to the scope of the duties and responsibilities. Equal pay should correspond to equal work within the same jurisdiction.

(12) Salary ranges which provide for a number of salary steps should be substituted for fixed salaries. Top classes are excepted, there being cases where fixed payment may be preferred.

(13) The possibility of revision of payment scales as determined by new economic conditions.

(14) Criteria for payment of special money allowances for bardslup or risk.

(15) Payment scales should be such as to attract prospective employees and retain capable personnel in the civil services.

\section{RECRUITMENT AND SELECTION}

(16) The best candidates should be attracted, recruited and selected for the civil service careers.

(17) Selection should be based on the merit principle.

(18) A clear distinction should be made between political posts and positions in the civil service.

(19) Selection for the career service should made through open competitive examinations.

(20. Prior to any selection process, a well-planned recruitment programme should be carried out, with the purpose of attracting the most capable candidates to the civil service.

(21) A staff specialized in the elaboration and rating of examinations should be meintained in the personnel services.

(22) The units to which recruitment is entrusted should adopt methods and procedures considered the most convenient to the application of the merit system.

(23) The possibility of permanent positions being temporarily and exceptionally filled without competitive examinations.

(24) Temporary employees should acquire permanent status only upon having qualified through examinations.

(25) Place of birth and residence should not be taken into account in the federal level. Local residents or native-born candidates should be given preference in the regional or municipal levels. 
(26) Recruitment and classification services should be articulated in order to decide upon the requirements for the several positions.

(27) The probation period is one of the aspects of selection to be particularly recommended.

(28) Both sexes should be given equal opportunities to compete for positions which can be inclifferently filled by either.

\section{EMPLOXEE EVOLUATION}

(29) The advisahili'y of an analytical appraisals of the civil servants; statements of its methods of procedure. ratings.

(30) Evoluation through "employee evoluations" "performance ratings" "efficiency

(52) $P_{1}$ oper relations between management and the employees should be maintained in all public agencies. Yet tindue stress must not be placed on the comforts and desires of exiployees to the detriment of the public interest.

(53) Personnel officers should discuss with the employees their personal problems and difficulties associated with their employment.

(54) The morale of the employees depends on economic considerations but also on good working conditions, sense of security and achievement, and of being a member of an efficient and useful organization.

(55) Public employees should have the right to join, or refrain from joining any lawful employee association.

(56) A machinery for negotiation or consultation between the administration and empluyee orgenizations is desirable, where representative and responsible employees organizations are avai'able or can be developed. Arbitration courts are also of value.

(57) Strikes are irreconcilable with the fundamental duty of civil servents.

(53) Management should encourage recreational, social and welfare activities and organizations for the employees.

(59) Systems of emiployee suggestions and honour awards programmes are commended as means of encouraging employee participation and interest in efficiency and productivity.

\section{DISCIPLINE}

(60) Civil servents are citizens of the State and subject to the laws of the country. office.

(61) Good discipline is required of a civil servant inside as well as outside his

(62) The best interest of the public service will be met most effectively by a fair and equitable treatment of employees.

(63) Supervisors must provide leadership and example to employees. If an employee's performance is unsatisfactory, appropriate disciplinary action should be taken.

(64) Ir all cases where disciplinary action is to be taken, the principle of like penalties for like offences should be applied, irrespective of racial, religious, social, political or any other similar factors.

(65) Limployees should be notified of any disciplinary action to be taken against them and also given oportunity to offer their defense and to appeal against the decision.

\section{RETIREMENT}

(66) There should be a compulsory retirement age for all employees in all agencies.

(67) Pension or retirement schemes for public employees should be provided and may be a part of a tiztional social security programme.

(31) The value of the system of evoluation and the ability and objectivity of the person to which it is entrusted; duties of such person.

(32) The employees should be notified of their rating and allowed to appeal adverse decisions,

(33) The reports made at the end of probation periods as an important type of etficiencv reting. 


\section{PROMOTION}

(34) The paramount importance of promotion rules and regulations.

(35) The impartial character of a well-organized and fair promotion system.

(36) The merit principle as the soundest foundation of a promotion system. The principle of seniority also to be applied.

(37) Promotion procedures should based on the merit principle.

(38) A general promotion plan should take into account the recruitment of new civil servents for vacant initual positions.

(39) The central personnel agency entrusted with promotion revision within a number of jurisdrctions. Such methods is to be recommended to under-developed jurisdictions.

\section{PLACEMENT}

(40) The adequate placement of every servant is fundamental to personnel administration.

(41) Transfer of the civil servants in the same grade or the same level recommended in order to cive them experience in different segments of service.

\section{TRAINING OF CIVIL SERVANTS}

(42) Training of civil servants is an important responsability of personnel services.

(43) Training programmes are especially needed in countries where educational systems are not well organized.

(44) Training should be efficiently and systematically planned; in most instances, it whould be carried out by local personnel agencies.

(45) Formal training courses should be provided only to meet definite necessities of the services.

(46). Training courses provided by the departments should be directed by the agencies, seing advisable to have the collaboration of an expert to plan and organize such courses.

(47) Training may comprise pre-induction courses, in-service training courses, special cotirses, correspondence courses, advanced courses, college courses, etc.

(48) Ability to guide sucessifully as a requirement for the position of supervisors.

(49) Both induction training and in-service training should be provided, whenever possible, during regular working hours.

- (50) The advisable practice of granting leaves of absence for study purposes is to be recommended.

(51) Attention should be given by public personnel agencies to the.

(68) Where there a compulsory contributory scheme, the employees should be represented on the board which administers the pension fund, if there is such a board.

(69) Pension funds and policies should be centrally controlled in each jurisdiction, and the administration should accept reponsibility for any actuarial deficit in the funds.

(70) Provision should be made for the granting of pensions to employees before they reach the normal retiring age, if they retire on medical gounds.

(71) Pension schemes should provide for widows and other close dependentes in the cvent of death of the employees, subject to appropriate eligibility conditions.

(72) The amounts of pensions currently paid schould be reviewed and adjusted whenever necessary on account of changes in economic conditions.

(73) Where pension schemes are on a contributory basis, employees who voluntarily leave the service prior to the retirement age should be refunded of a sum at least equivalent to their own contributions.

(74) There should be provision, after hearing, for requiring retirement before the normal retiring age in case of employees of diminished efficiency with lengthy service who have, not committed any offence that justify dismissal.

\section{TENURE}

(75) The employees should be protected against arbitrary dismissal. On the other hand, persons who are incompetent must be readily dismissed from the civil service. 
(76) Whenever necessary to reduce a permanent establishement, displaced efficient career employes should (1) be transferred to other posts in the same grade (2) or superannuated on "abolition of office" terms.

\section{SAFETY AND HEALTH}

(77) Systematic efforts should be made to protect the safety and health of public employees.

(78) Employees who are disabled in the course of their duty should be provided for during their disability.

\section{HOURS OF WORK}

(80) The hours of work for government employees should not exceed the prevailing hours of work in private industry. They should not, however, be unreasonably short in comparison with private industry.

(80) Overtime duty may be required of public service employees and appropriate adequate compensation whould be provided for such duty.

\section{LEAVE OF ABSENCE}

(81) Adequate provision should be made for leave of absence with pay for government employees, including both vacation and sick leave.

Na faita de reais perspectivas de acesso, características do verdadeiro sentido de carreira, nenhum estímulo existe, atualmente, para o funcionalismo, no tocantc au aprimoramento de seus conhecimentos.

(Trecho do relatório da Comissão de Classificação de Cargos, 1954) 